\title{
Optimalisasi Pendekatan MIKiR Sebagai Solusi Pembelajaran Abad 21 Bagi Guru SD Muhammadiyah Kota Medan
}

\author{
Eko Febri Syahputra Siregar*1, Suci Perwita Sari², \\ 1,2Program Studi Pendidikan Guru Sekolah Dasar, Fakultas Keguruan dan Ilmu Pendidikan, Universitas \\ Muhammadiyah Sumatera Utara \\ *e-mail: ekofebrisyahputra@umsu.ac.id ${ }^{1}{ }_{\text {suciperwitasari@umsu.ac.id }}^{2}$
}

\begin{abstract}
The study aims to answer the learning challenges on the 21st century. Teachers are required to improve their abilities, especially in managing student-oriented learning. Teacher creativity is the basis for designing meaningful learning. Participants of this activity were teachers of SD Muhammadiyah 29 Sei Mencirim and SD Muhammadiyah 38 Medan Krio. The target of this activity is that teachers are able to design active learning scenarios that can be applied in class. The methods for implementing this activity are: 1) Initial meeting with school principals, 2) Training activities, 3) Evaluation, and 4) Follow-up plans. Based on the results of the activity, the teachers have been able to design active learning scenarios and 21st century skills. The implementer hopes that participants will familiarize themselves with implementing the results of activities in supporting the learning being carried out and can pass them on to other teachers.
\end{abstract}

Keywords: MIKiR Approach, Active Learning and 21st Century Skills

\begin{abstract}
Abstrak
Kegiatan ini bertujuan menjawab tantangan pembelajaran abad 21. Para guru dituntut untuk meningkatkan kemampuan khususnya dalam mengelola pembelajaran yang berorientasi pada siswa. Kreativitas guru menjadi dasar dalam merancang pembelajaran yang bermakna. Peserta kegiatan ini yaitu guru SD Muhammadiyah 29 Sei Mencirim dan SD Muhammadiyah 38 Medan Krio. Target kegiatan ini adalah para guru mampu merancang skenario pembelajaran aktif yang dapat diterapkan di kelas. Metode pelaksanaan kegiatan ini yaitu :1) Pertemuan awal dengan para kepala sekolah, 2) Kegiatan pelatihan, 3) Evaluasi, dan 4) Rencana tindak lanjut. Berdasarkan hasil kegiatan, bahwa para guru sudah mampu merancang skenario pembelajaran aktif dan keterampilan abad 21. Pelaksana berharap agar peserta membiasakan diri dalam menerapkan hasil kegiatan dalam dalam mendukung pembelajaran yang dilaksanakan serta dapat meneruskannya kepada guru-guru lainnya.
\end{abstract}

Kata kunci: Pendekatan MIKiR, Pembelajaran Aktif dan Keterampilan Abad 21

\section{PENDAHULUAN}

Salah satu tujuan penting proses pembelajaran adalah mengembangkan potensi siswa. Pembelajaran diharapakan mampu memberikan ruang kepada siswa untuk aktif tanpa ada keraguan dan rasa takut selama pembelajaran. Perlu diketahui juga, bahwa pembelajaran merupakan ujung tombak keberhasilan dalam dunia pendidikan. Sebaik apapun sistem pendidikan tanpa adanya pembelajaran yang berkualitas, sangat tidak mungkin dapat mencapai tujuan yang dikehendaki. Maka dari itu tentunya tujuan pembelajaran yang hendak dicapai berorientasi pada kompetensi kognitif, afektif maupun psikomotorik(Sari, Suci Perwita; Siregar, 2020).

Ketiga kompetensi tersebut harus mampu dikuasai peserta didik sebagai produk belajar. Di era saat ini, keberhasilan pembelajaran tidak dapat lagi hanya diukur dari sisi pengetahuan (kognitif), melainkan juga harus memperhatikan afektif dan psikomotorik. Peserta didik harus dapat menguasai ketiga kompetensi tersebut agar mampu menjawab tantangan global. Kemampuan tersebut diatandai dengan keterampilan berpikir kritis, kemampuan berkomunikasi secara efektif, berinovasi dan memecahkan masalah melalui negosiasi dan kolaborasi. Kemampuan inilah yang saat ini dikenal dengan Keterampilan abad 21. 
Menurut (Luna, 2015) the US-based Partnership for 21st Century Skills, a coalition of business leaders and educators, proposed a Framework for 21st Century Learning, which identified essential competencies and skills vital for success in twenty-first century work and life. These included 'The 4Cs' - communication, collaboration, critical thinking and creativity, which are to be taught within the context of core subject areas and twenty-first century themes. Kompetensi ini sangat penting diajarkan kepada peserta didik dalam konteks abad ke-21 dan diharapkan dapat menjadi modal awal yang bernilai sangat penting dalam mempersiapkan masa depan bangsa Indonesia yang kompeten dan kompetitif, serta berjiwa tangguh dalam menghadapi persaingan yang cukup ketat dalam lingkup global maupun regional.

Selain keempat kompetensi tersebut, dirumuskan juga empat prinsip yang dikenal sebagai empat pilar pendidikan yaitu learning to know, lerning to do, learning to be dan learning to live together. Kerangka pemikiran ini dirasa masih relevan dengan kepentingan pendidikan saat ini dan dapat dikembangkan sesuai dengan keperluan di abad ke-21 tentunya hal ini memberikan peluang kepada peserta didik untuk menikmati pengalaman belajar yang terjadi agar pembelajaran semakin bermakna.

Pendidik dalam hal ini guru tentunya memiliki peran yang sangat penting dalam mendukung ketercapaian dari keterampilan abad 21 yang diharapkan. Menurut (Kartimi et al., 2019) peran penting seorang guru abad ke-21 adalah sebagai role model untuk kepercayaan, keterbukaan, ketekunan dan komitmen bagi siswanya dalam menghadapi ketidakpastian di abad ke-21. Sejalan dengan itu (Rahayu \& Firmansyah, 2019) mengungkapkan bahwa persiapan mengajar mencerminkan apa yang akan dilakukan guru dalam memberikan kemudahan belajar kepada siswa, bagaimana melakukannya dan mengapa guru melakukan itu sehingga tidak menemui kejenuhan bagi peserta didik.

Menurut (Guntoro, 2020) munculnya kejenuhan bagi anak-anak dalam kegiatan belajar menggunakan cara konvensional dikarenakan anak-anak pada zaman sekarang atau biasa disebut sebagai anak-anak generasi alfa yang sudah terbiasa dengan hal-hal menarik dalam kegiatan belajar dengan menggunakan bantuan teknologi. Maka dari itu diperlukan adanya tahapan bagaimana mahasiswa mengalami, berinteraksi dan berkomunikasi serta refleksi dalam setiap perkuliahan yang terjadi sehingga dapat diketahui ketercapaian tujuan dalam setiap perkuliahan yang telah dilalui.(Siregar, Eko Febri Syahputra ; Sari, 2020)

Berdasarkan hasil observasi yang dilakukan pada dua sekolah yaitu SD Muhammadiyah 38 Medan Krio dan SD Muhammadiyah 29 Sei Mencirim yang menjadi mitra pada Program Kemitraan Masyarakat (PKM) ini, yaitu masih belum terlihat keaktifan peserta didik dalam kegiatan pembelajaran. Pembelajaran yang dilakukan masih berfokus kepada guru (Teacher Centered Learning) belum mengarah kepada Student Centered Learning.

Maka dari itu dirasa perlu adanya suatu langkah untuk membekali guru dalam menyikapi tuntutan pembelajaran abad 21 tersebut. Solusi yang ditawarkan adalah dengan melakukan kegiatan pelatihan yang diberi judul "Optimalisasi Pendekatan MIKiR Sebagai Solusi Pembelajaran Abad 21 Bagi Guru di SD Muhammadiyah Kota Medan".
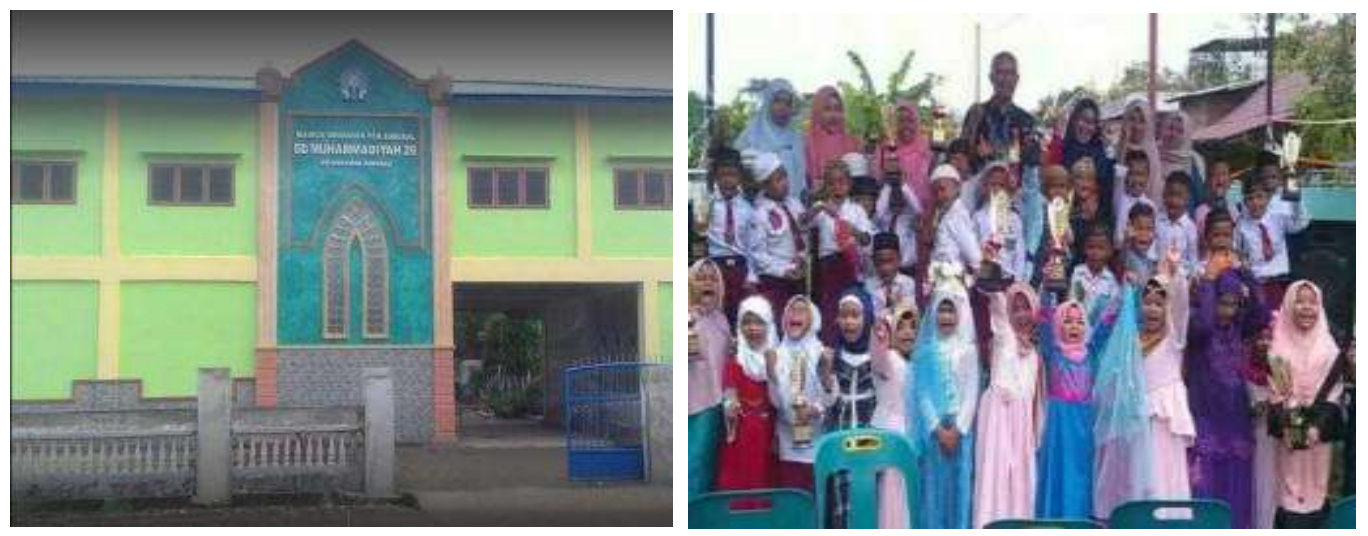

Gambar 1. Gedung SD Muhamadiyah 29 Sei Mencirim dan Gambar B Aktivitas Siswa SD Inovatif Muhammadiyah 38 Medan Krio 
Pembelajaran MIKiR adalah suatu pendekatan pembelajaran yang mendorong keaktifan pada peserta didik. MIKiR merupakan singkatan dari Mengalami, Interaksi, Komunikasi dan Refleksi. Merujuk hal tersebut di atas, maka pembelajaran aktif dengan pendekatan MIKiR dapat dijadikan solusi yang sangat baik dalam mengembangkan keterampilan guru pada umumnya serta keterampilan abad 21 pada khususnya karena memiliki tujuan yang sama agar siswa aktif dalam pembelajaran sedangkan guru hanya sebagai fasilitator.

Menurut (Foundation, 2018) bahwa unsur pembelajaran aktif (MIKiR) bukan urutan. Kegiatan dari setiap unsur juga dapat terjadi beberapa kali dalam satu proses pembelajaran. Ada kalanya beberapa unsur tersebut muncul bersamaan.

Disamping itu, pembelajaran aktif dengan pendekatan MIKiR menjadi sangat penting karena (1) mengalami (dalam belajar melibatkan banyak indera sehingga pemahaman konsep akan lebih mantap); (2) Interaksi (dapat mendorong siswa untuk bereaksi terhadap pendapat siswa lain dan dapat menimbulkan 'refleksi' pada diri siswa lain tersebut); (3) Komunikasi (dapat memotivasi siswa untuk berani dan lancar dalam mengungkapkan gagasan); (4) Refleksi (dapat memunculkan sikap untuk mau menerima kritik dan memperbaiki diri, baik gagasan, hasil karya maupun sikapnya) (Foundation, 2018). Maka dari itu dapat disimpulkan bahwa keterampilan abad 21 (4C) memiliki persamaan dengan pendekatan MIKiR.

\section{METODE}

Pelaksanaan kegiatan dilakukan melalui pelatihan yang diberikan kepada guru-guru terkait pembelajaran aktif dengan pendekatan MIKiR dan Pembelajaran Abad 21. Pada pelatihan ini akan menghasilkan produk skenario pembelajaran yang kegiatannya berfokus pada keaktifan siswa sesuai tuntutan pembelajaran abad 21.

Kegiatan PKM ini dilakukan melalui empat tahapan, yaitu :1) Persiapan, pada tahapan ini kelompok pengabdian melakukan observasi terhadap pembelajaran yang dilakukan oleh guru di dalam kelas. Hal ini dilakukan guna mengetahui aktivitas guru dan siswa dalam pembelajaran; 2) Pelaksanaan, tim Pelaksana akan melakukan pelatihan tentang pembelajaran aktif melalui pendekatan MIKiR sebagai solusi pembelajaran abad 21dengan menghasilkan skenario pembelajaran yang merujuk pada aktifitas siswa dalam pembelajaran (student centered learning); 3) Monitoring, tahapan ini dilakukan dengan cara Pelaksana melakukan kunjungan ke lokasi SD Muhammadiyah 38 Medan Krio dan SD Muhammadiyah 29 Sei Mencirim untuk melihatn aktivitas guru mengajar dengan penerapan pendekatan MIKiR pada saat proses pembelajaran; dan 4) Evaluasi, merupakan tahapan yang terakhir. Pada tahapan ini dilakukan evaluasi terhadap hasil yang telah dicapai para peserta pelatihan. Evaluasi dilakukan dengan cara mengumpulkan skenario pembelajaran dengan pendekatan MIKiR yang telah dilaksanakan pada saat pembelajaran di kelas masing-masing serta produk hasil pembelajaran berupa karya siswa. Setelah itu, para peserta melakukan refleksi bersama peneliti guna mengetahui keberhasilan dan kekurangan pada saat pembelajaran yang telah dilalui dan untuk perbaikan pelaksanaan pembelajaran kedepannya dengan pendekatan MIKiR. Indikator ketercapaian program ini yaitu apabila $80 \%$ guru-guru yang mengikuti kegiatan ini sudah memahami dan mampu membuat skenario pembelajaran untuk tema pembelajaran.

\section{HASIL DAN PEMBAHASAN}

Hasil yang diperoleh pada Program Kemitraan Masyarakat (PKM) dengan judul “Optimalisasi Pendekatan MIKiR Sebagai Solusi Pembelajaran Abad 21 bagi Guru SD Muhammadiyah Kota Medan" dan melibatkan peserta dari SD Muhammadiyah 29 Sei Mencirim dan SD Muhammadiyah 38 Medan Krio adalah dihasilkannya skenario pembelajaran aktif merujuk pada keterampilan abad 21 yang telah disusun oleh guru yang menjadi peserta kegiatan. Skenario yang dimaksud juga sebagai rujukan atas Surat Edaran Mendikbud No. 14 tentang Penyederhanaan Rencana Pelaksanaan Pembelajaran (RPP) atau yang lebih dikenal di kalangan guru dengan sebutan RPP satu lembar. Menurut (Raehang, 2014) pembelajaran aktif 
mengkondisikan agar peserta diidk melakukan pengalaman belajar yang bermakna dan senantiasa berfkir tentang apa yang akan dilakukan selama pembelajaran.

Kegiatan ini dilaksanakan pada hari Senin tanggal 22 Juni 2020. Dalam melaksanakan PKM ini, Pelaksana melaksanakan kegiatan sesuai dengan langkah-langkah yang direncanakan pada bagian sebelumnya. Adapun langkah-langkah tersebut adalah sebagai berikut :

Tabel 1. Langkah-Langkah Kegiatan PKM

\begin{tabular}{|c|c|c|c|}
\hline No & Tahapan & Kegiatan & Partisipasi Mitra \\
\hline 1 & Persiapan & $\begin{array}{l}\text { a) Observasi terhadap pembelajaran } \\
\text { yang dilakukan guru didalam kelas, } \\
\text { serta wawancara mengenai hal yang } \\
\text { menjadi kesulitan/pengahambat } \\
\text { bagi guru dalam melaksanakan } \\
\text { pembelajaran. } \\
\text { b) Melakukan kesepakatan dengan } \\
\text { sekolah mitra terkait kegiatan yang } \\
\text { akan dilaksanakan. } \\
\text { c) Menentukan jumlah peserta yang } \\
\text { mengikuti kegiatan. } \\
\text { d) Menentukan waktu dan tempat } \\
\text { dilaksanakan kegiatan. } \\
\text { e) Menyediakan sarana dan prasarana } \\
\text { pendukung kegiatan agar } \\
\text { berlangsung dengan baik. }\end{array}$ & $\begin{array}{l}\text { Memberikan keterangan dan } \\
\text { informasi yang diperlukan } \\
\text { oleh pelaksana. }\end{array}$ \\
\hline 2 & Pelaksanaan & $\begin{array}{l}\text { a) Memberikan materi kepada para } \\
\text { peserta tentang pembelajaran aktif } \\
\text { dengan pendekatan MIKiR, } \\
\text { pembelajaran yang mendukung } \\
\text { keterampilan abad } 21 \text { serta } \\
\text { b) Pendampingan dalam penyusunan } \\
\text { skenario pembelajaran sesuai Surat } \\
\text { Edaran Mendikbud RI No. } 14 \text { tahun } \\
2019 \text { Tentang Penyederhanaan RPP. }\end{array}$ & $\begin{array}{l}\text { Menyediakan tempat dan } \\
\text { sarana yang mendukung serta } \\
\text { berperan aktif dalam } \\
\text { mengikuti kegiatan. }\end{array}$ \\
\hline 3 & $\begin{array}{l}\text { Evaluasi dan } \\
\text { Refleksi }\end{array}$ & $\begin{array}{l}\text { a) Memberikan penilaian atas skenario } \\
\text { pembelajaran yang telah disusun. } \\
\text { b) Peserta memperbaiki skenario } \\
\text { pembelajaran yang telah disusun } \\
\text { berdasarkan masukan yang } \\
\text { diperoleh dari Pelakasana. }\end{array}$ & 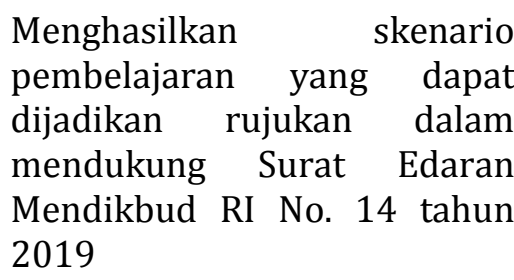 \\
\hline 4 & Tindak lanjut & $\begin{array}{l}\text { Para peserta semakin mahir dalam } \\
\text { menyusun skenario pembelajaran aktif } \\
\text { dan menerapkannya } \\
\text { pembelajaran di dalam kelas. }\end{array}$ & $\begin{array}{lr}\text { Menjalin komunikasi } & \text { dan } \\
\text { sepakat untuk } & \text { terus } \\
\text { melakukan inovasi } & \text { dalam } \\
\text { pembelajarn } & \text { guna } \\
\text { meningkatkan mutu } & \text { sekolah } \\
\text { yang lebih baik. }\end{array}$ \\
\hline
\end{tabular}




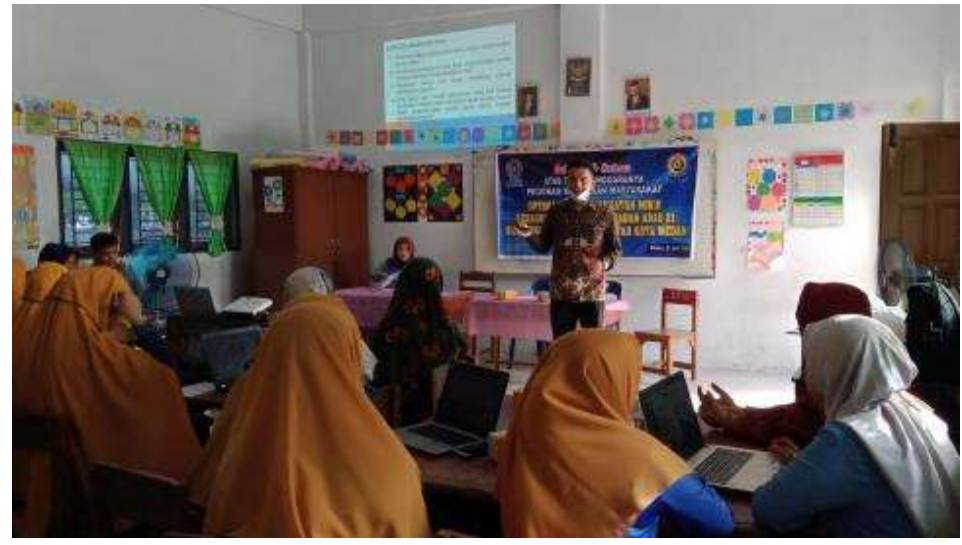

Gambar 2. Pelaksana Menyampaikan Materi Kegiatan

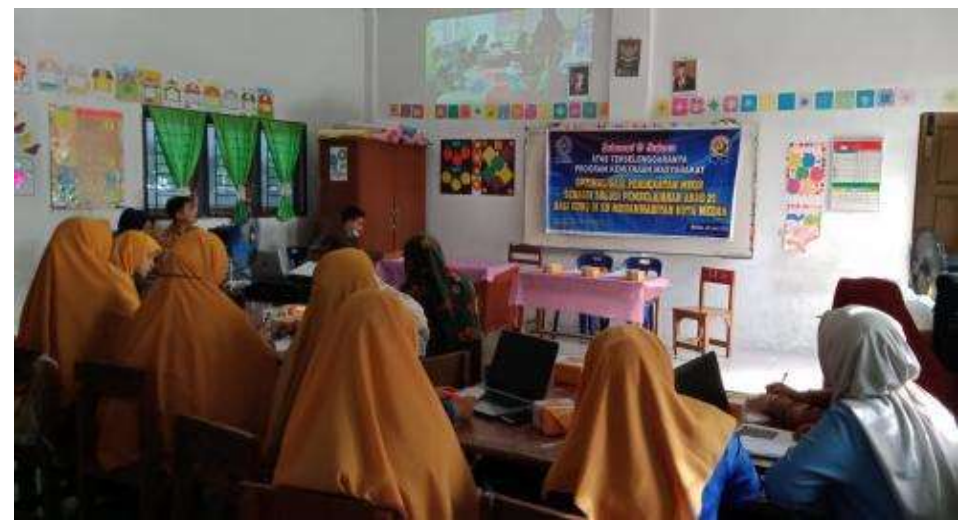

Gambar 3. Peserta Mengamati Video Pembelajaran Aktif

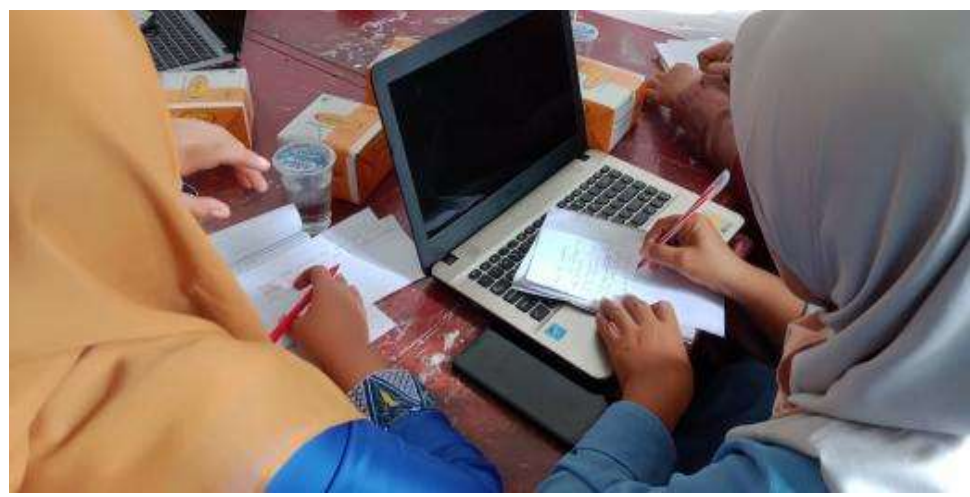

Gambar 4. Peserta Menuliskan Hasil Pengamatan Video

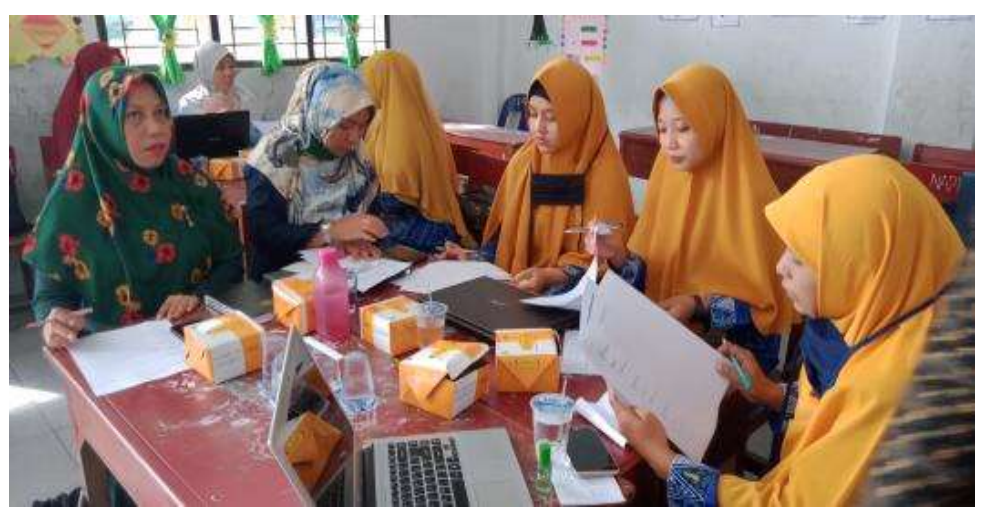

Gambar 5 . Peserta sedang Menyusun Skenario Pembelajaran 
Keberhasilan kegiatan pengabdian ini dilihat dari kemampuan guru merancang skenario pembelajaran yang berorientasi pada pembelajaran aktif. Menurut (Pernantah, 2019) metode MIKiR sangat simple dan sederhana, maka mudah untuk menyusun skenario pembelajarannya sehingga tidak akan menyulitkan para dosen dalam mempersiapkannya.

Dalam skenario yang disusun tidak lagi menuntut kegiatan guru melainkan aktivitas yang dilakukan peserta didik. Karena pada dasarnya Pendidikan merupakan usaha mempersiapkan peserta didik agar dapat tumbuh kembang secara baik dan mampu beradaptasi dengan berbagai situasi dan kondisi yang dihadapi dalam menjalankan (Siregar, Eko Febri Syahputra ; Damailia, 2020). Para peserta menyusun skenario secara berpasangan berdasarkan kelas yang diampu. Sehingga setiap tingkatan kelas terdiri atas 2 (dua) orang peserta atau kerja berpasangan. Pelaksana juga menyarankan skenario yang disusun juga dapat disesuaikan dengan situasi pembelajaran dengan pendemi Covid-19 ataupun pembelajaran daring. Hasil ini tentunya sejalan dengan hasil penelitian (Ninik Pujianti, Ernawati Saptaningrum, 2019) yang memperoleh hasil bahwa pendekatan MIKiR memberikan pengaruh yang lebih baik daripada pembelajaran konvensional terhadap kemampuan memecahkan masalah.

\section{KESIMPULAN}

Berdasarkan kegiatan pengabdian yang telah dilakukan kepada guru-guru di lingkungan SD Muhammadiyah 29 Sei Mencirim dan SD Muhammadiyah 38 Medan Krio, maka dapat disimpulkan bahwa :1) Kegiatan ini dapat dikatakan berhasil bila diukur dari jumlah peserta yang mengikuti sesuai dengan yang disepakati, serta kehadiran peserta yang menunjukkan rasa antusias dilihat dari kehadiran peserta di tempat kegiatan yaitu 30 menit lebih dulu sebelum acara dimulai serta keaktifan dan rasa ingin tahu selama kegiatan berlangsung; 2) Para guru yang mengikuti kegiatan ini sudah mampu memahami sebahagian besar materi yang disampaikan dalam kegiatan ini, diantanya pembelajaran aktif dengan pendekatan MIKiR serta pembelajaran dengan menekankan keterampilan abad 21, dan 3) Mampu merancang skenario pembelajaran aktif dengan pendekatan MIKiR sesuai dengan tuntutan keterampilan abad 21.

\section{DAFTAR PUSTAKA}

Foundation, T. (2018). Modul I Praktik yang Baik. In Modul I Praktik yang Baik.

Guntoro, G. B. (2020). Pemanfaatan Aplikasi Sebagai Media Bantu Edukasi Agama Islam Untuk Anak Usia Dini. Dinamisia: Jurnal Pengabdian Kepada Masyarakat, 4(1), 150-158. https://doi.org/10.31849/dinamisia.v4i1.3339

Kartimi, K., Mulyani, A., \& Riyanto, O. R. (2019). Pemberdayaan Guru Dalam Implementasi Pembelajaran Abad 21. Dimasejati: Jurnal Pengabdian Kepada Masyarakat, 1(2), 160-170. https://doi.org/10.24235/dimasejati.v1i2.5815

Luna, C. (2015). The Futures of Learning 2: What Kind of Learning for The 21st Century? Education Research and Foresight, 1-14.

Ninik Pujianti, Ernawati Saptaningrum, J. S. (2019). Perbedaan Pengaruh Model Pembelajaran "MIKIR" dan Creative Problem Solving (CPS) Pada Pokok Bahasan Usaha Dan Energi Berbantuan LKS Terhadap Kemampuan Memecahkan Masalah. UPGRIS, 53(9), 33-37. https://doi.org/10.1017/CB09781107415324.004

Pernantah, P. S. (2019). Desain Skenario Pembelajaran Aktif Dengan Metode "Mikir" Pada Mata Kuliah Pendidikan IPS. Indonesian Journal of Social Science Education (IJSSE), 1(2), 145155. https://doi.org/10.29300/IJSSE.V1I2.1929

Raehang. (2014). Pembelajaran Aktif Sebagai Induk Pembelajaran Kooperatif. Jurnal Al-Ta'dib, 7(1), 149-167. ejournal.iainkendari.ac.id/al-tadib/article/view/249/239

Rahayu, G. D. S., \& Firmansyah, D. (2019). Pengembangan Pembelajaran Inovatif Berbasis Pendampingan Bagi Guru Sekolah Dasar. Abdimas Siliwangi, 1(1), 17. https://doi.org/10.22460/as.v1i1p17-25.36 
Sari, Suci Perwita; Siregar, E. F. S. (2020). Pengaruh Model Pembelajaran Abad 21 4Cs Dalam Meningkatkan Keterampilan Membuat Pertanyaan Tingkat Tinggi Mahasiswa PGSD FKIP Pada Materi Gejala Alam T.A. 2019/2020. Jurnal Ilmiah Aquinas, 3(2), 208-215.

Siregar, Eko Febri Syahputra; Damailia, E. (2020). Pembelajaran Online Sebagai Bentuk Penguatan Pendidikan Selama Pandemi Covid-19 Di SD Muhammadiyah 03 Kota Medan. Jurnal Ilmiah Aquinas, III(2), 306-315.

Siregar, Eko Febri Syahputra; Sari, S. P. (2020). Pengaruh Model Pair Checks Terhadap Komunikasi Interpersonal Mahasiswa PGSD FKIP UMSU. Jurnal Tematik, 10(2), 69-73. 